\title{
Community Engagement of Adolescents in the Development of a Patient- Centered Outcomes Tool for Adolescents with a History of Hypospadias Repair
}

Katherine H. Chan, MD, MPH ${ }^{a, b}$, Janet Panoch, $M^{a}{ }^{a}$, Aaron Carroll MD, MS ${ }^{b}$, Stephen Downs, MD, $\mathrm{MS}^{\mathrm{c}}$, Mark P. Cain, MD ${ }^{\mathrm{a}}$ Richard Frankel, PhD, ${ }^{\mathrm{d}}$ Brandon Cockrum, MFA, Courtney Moore, BFA, Sarah Wiehe, MD, MPH

aDepartment of Urology, Indiana University School of Medicine,

Department of Pediatrics: ${ }^{b}$ Center for Pediatric and Adolescent Comparative Effectiveness Research and ${ }^{\mathrm{C} C h i l d r e n ' s ~ H e a l t h ~ S e r v i c e s ~ R e s e a r c h ~ C e n t e r, ~}$

dDepartment of Medicine, Indiana University School of Medicine, Indianapolis, Indiana and Cleveland Clinic Learner Institute, Cleveland, Ohio

\section{Corresponding Author:}

Katherine H. Chan, MD, MPH

a705 Riley Hospital Drive, Riley Outpatient Center, 4230, Indianapolis, IN 46202

Phone: 216-269-7878; Fax: 001-317-944-7481; e-mail: kchubert@iupui.edu

Panoch: jpanoch@iupui.edu; Carroll: aaecarro@iu.edu; Downs: stmdowns@iu.edu;

Cain: mpcain@iupui.edu; Frankel: rfrankel@iu.edu; Cockrum: bcockrum@iu.edu;

Moore: crtnymre@iu.edu; Wiehe: swiehe@iu.edu

\section{Abstract word count: 398; Manuscript word count: 2,702}

Key words: pediatrics; hypospadias; qualitative research

Funding sources

- $\quad$ K23 Career Development Award (1K23DK111987-01) from the National Institutes of Health-

National Institute of Diabetes and Digestive and Kidney Diseases.

This is the author's manuscript of the article published in final edited form as:

Chan, K. H., Panoch, J., Carroll, A., Downs, S., Cain, M. P., Frankel, R., ... Wiehe, S. (2019). Community Engagement of Adolescents in the Development of a Patient-Centered Outcomes Tool for Adolescents with a History of Hypospadias Repair. 
- The Patient Engagement Core is supported by the Indiana Clinical and Translational Sciences Institute funded in part by the National Institute for Advancing Translational Science, grant number TR001107. 


\section{Extended Summary}

Introduction: Hypospadias may lead to long-term issues with urination, sexual function and psychosocial well-being. Limited evidence exists regarding the healthcare communication preferences of male adolescents regarding sensitive topics.

Objective: The purpose of this qualitative study was to explore the healthcare communication preferences of male adolescents regarding sensitive topics (e.g. urinary and sexual issues) and engage them in in the initial stages of development a patient-centered outcomes tool for adolescents with a history of hypospadias repair.

Study Design: A multi-disciplinary team with communication design expertise, pediatric urology experts, and health services researchers developed a self-reported toolkit for adolescent patients who had hypospadias repair as children. The toolkit featured short writing/diagramming exercises and scales to facilitate participant reflections about genital appearance, urination, sexual function and psychosocial well-being. We recruited students from two local high schools for two focus groups to obtain feedback about the usability/acceptability of the toolkit's appearance/content. We inquired about language preferences and preferred format and/or setting for sharing sensitive information with researchers. The focus groups were audio recorded, professionally transcribed, checked for accuracy and analyzed by two coders using qualitative content analysis. Major themes and subthemes were identified and representative quotes were selected.

Results: We conducted two focus groups in January 2018 with 33 participants, ages 14-18. Participants preferred language that would make patients feel comfortable as well as serious, clinical language rather than slang terms/sexual humor (Extended Summary Table). They recommended avoidance of statements implying that something is wrong with a patient or statements that would pressure the patient into providing answers. They suggested fill-in-the-blank and open-ended responses to 
encourage freedom of expression and colorful graphics to de-emphasize the test-like appearance of the toolkit. Most participants preferred a toolkit format to a one-on-one interview to discuss sensitive topics such as urinary or sexual issues. Participants would prefer either a male interviewer or would like to have a choice of interviewer gender for individual qualitative interviews, and they recommended a focus group leader with a history of hypospadias repair.

Discussion: This study provides a rich description of a group of male high school students' experiences with healthcare providers and researchers. Its qualitative design limits generalizability and our findings may not be similar to adolescents with a history of hypospadias repair.

Conclusion: We used focus group feedback on the toolkit prototype to refine the tool for use in a future study of adolescents with history of hypospadias repair. 


\section{Introduction}

Hypospadias, a urethral opening on the underside of the penis with associated chordee and foreskin abnormalities, may lead to long-term issues with penile appearance, urination, sexual and reproductive function and psychosocial well-being. Prior studies regarding the long-term outcomes of hypospadias repair have focused on surgeon-centered outcomes (e.g. anatomical results and postoperative complications) and patient reported outcomes derived from surgeons' assumptions about which domains are important.[1-9] These studies have used a combination of validated and nonvalidated surveys to assess primarily cosmetic satisfaction and urination.[10] None were developed with patient-centered input using research tools such as interviews or focus groups. In addition, these surveys did not address self-perception, embarrassment, satisfaction with urinary/sexual function or quality of life.[10] Only one study used qualitative methodology to ascertain which hypospadias outcomes are most important to parents, and no studies have explored these issues in an open-ended fashion with adolescents.[11] The development of true patient-centered outcomes is important because patient variables, rather than surgical variables, are most strongly associated with decisional regret after hypospadias surgery.[12]

In order to develop meaningful patient-centered outcomes measures for a specific patient population (i.e. patients with a history of hypospadias repair) it is also important to understand the healthcare communication preferences of the target group (i.e. male adolescents). There is limited evidence regarding adolescents' preferences for communication with healthcare providers and researchers about sensitive topics although distrust of medical professionals is commonly reported.[13,

14] Most qualitative studies about adolescent sexuality have focused on attitudes, knowledge and choices regarding sexual and reproductive health. $[15,16]$ Lee et al. found that $20 \%$ of teens believed that their clinician would inform their parents if they disclosed that they were having sex.[13] Mustanski 
et al. noted that most lesbian, gay, bisexual and transgender adolescents would be reluctant to participate in research about sexually transmitted diseases if parental permission were required.[14]

In order to address these critical research gaps regarding adolescents' healthcare communication preferences that will ultimately inform the development of patient-reported outcomes measures for hypospadias surgery and, we sought to: a) explore the healthcare communication preferences of male adolescents without a clinical history of hypospadias regarding sensitive topics (e.g. urinary and sexual issues) and b) engage them in in the initial stages of development of a long-term patient-centered outcomes tool for patients with a history of hypospadias repair.

This work is the initial stage in a larger project that aims to develop a patient-centered outcomes measure for adolescents with a history of hypospadias repair as children. Many hypospadias patients do not have regular urologic follow-up into adolescence which makes it difficult to recruit them for research studies. We hypothesized that a self-reported toolkit format would be acceptable to adolescents because of the sensitive nature of the research and the potential for distrust of medical providers.

\section{Materials and Methods}

\section{Study sites and participants}

Adolescents from two local high schools were recruited to participate in 1 of 2 focus groups held at their respective schools during school hours. They included a small, private, religiously-affiliated high school located in a suburban area and a large, racially diverse public high school located in an urban area. We used maximum variation sampling in selecting these schools to diversify the socioeconomic status, geographic location and racial/ethnic composition of the focus groups. Inclusion criteria were male gender, age 13-19 years and English fluency. Key outreach staff at each site,

\section{including teachers}


and administrators, assisted with identification of a convenience sample of youth interested in participating. These included students currently enrolled in a healthcare class and prior participants in focus groups at the respective schools. We sent a study information sheet to their parents and obtained written parental consent for participation. The focus group facilitator read the assent form to the participants, answered questions and obtained participant signatures to document assent prior to the beginning of the session.

\section{Interview guide}

The investigators developed a semi-structured interview guide containing open-ended questions

(Table 1). We explored the adolescents' preferences for exploring sensitive topics such as urinary and sexual issues with healthcare researchers including the type of language, data collection format and gender preference of the researchers. We did not inquire about the boys' personal experiences with their own urinary and/or sexual issues. We only inquired about their general preferences for discussing such issues with healthcare providers and researchers.

We also obtained feedback about the content and appearance of a self-reported toolkit we created for adolescents with a history of hypospadias repair as children. The toolkit includes "priority domains" for hypospadias outcome measures identified by Keays et al. based on interviews and focus groups with patients and healthcare providers.[11] These include satisfaction with appearance, urination and erections and overall well-being.[11] It features short writing exercises, diagram labeling exercises, and scales ranking activities to assist in reflections about these domains.

\section{Data collection}

Focus groups were conducted by two of the investigators (KC and JP) who were trained in focus group facilitation including the importance of limiting imposition of their own biases. Groups lasted 
approximately 90 minutes and were audio recorded, checked for accuracy by the researchers and professionally transcribed. Participants' responses were de-identified and they were compensated $\$ 40$ for their time. The Institutional Review Board approved the study.

\section{Data analysis}

Transcripts were professionally transcribed and imported into NVivo Pro qualitative research software (version 11, QSR International Pty, Ltd., Doncaster, Victoria, Australia) to facilitate grouping, sorting and cross-referencing of the data. Our multi-disciplinary team independently categorized (i.e. double coded) textual data using directed qualitative content analysis techniques.[17] Each code was defined and data were sorted into relevant coding categories. The initial codes were modified and additional codes were added as necessary to best reflect the content of the focus group data. Team members resolved discrepancies and reached consensus about the major themes and subthemes that were common to both focus groups.

\section{Results}

\section{Sample}

A total of 33 male adolescents aged 14-18 years participated in 1 of 2 focus groups in January 2018. The focus groups consisted of 16 and 17 participants, respectively. We did not collect race, ethnicity or socioeconomic status of the individual participants in order to ensure anonymity.

\section{Toolkit Feedback}

We identified themes and recommendations for revision of the appearance and content of the toolkit based on focus group feedback (Extended Summary Table). Participants suggested that the toolkit should provide education about hypospadias without making it seem like a test. For example, 
they recommended the use of lighter colors and graphics to make it look "less like a test" (Extended Summary Table). Figure 1 shows an example of the participants' suggested revisions for the appearance of the introductory page including lighter colors to make the journal more "inviting" and a graphic to reassure patients about the relatively common nature of the condition. Some participants discouraged the inclusion of any photographs of hypospadias anatomy due to concerns about patient discomfort. They suggested that a link to a medical website with reliable information about hypospadias would be preferable to a photograph (Figure 1). Other participants recommended a graphical illustration of an infant with hypospadias. In addition, they suggested fill-in-the-blank and open-ended responses to encourage freedom of expression. Participants felt that it was important to use the term "responses" instead of "answers" and emphasize that there are no right or wrong answers. The exercise depicted in Figure 2 asks the patient to consider how hypospadias makes him feel in various environments utilizing a Likert scale of emojis to describe his emotions. Participants suggested that we encourage freedom of expression by giving patients the option to assign more than one emotion to each environment, add their own emoji and explain their choices (Figure 2). They also suggested that we add "embarrassment" and remove "joy" from the list of emojis. Figure 3 depicts a scale that asks patients to rate how hypospadias has affected them in various areas of their life. Participants again emphasized the importance of giving patients opportunity to explain their choices (Figure 3).

Participants preferred language that would make patients feel comfortable as well as serious, clinical language rather than slang terms or sexual humor (Extended Summary Table). For example, they suggested using terms such as "urination" and "ejaculation" in lieu of more colloquial language. There was confusion about the terms "sexual function" and "quality of life." Participants thought that the term "sexual function" referred exclusively to sexual activity with a partner rather than erectile and ejaculatory function. They suggested that we define "quality of life" as "your attitude and what you think about the world." They also recommended avoidance of statements implying that something is 
wrong with a patient who has hypospadias. For example, they recommended changing the word "issue" to "condition" when referring to the patient's history of hypospadias. They also discouraged statements that would pressure the patient into providing answers. For example, they suggested removing the following statement: "you will be one of approximately 20 young men who will complete these journals." They were concerned that patients might feel pressured to share their responses if they knew that they were part of a small group. They recommended using the word "describe" instead of "explain" when instructing the patient about how to respond to the toolkit exercises. They also suggested emphasizing that the purpose of the study is to help us to understand an "issue that affects many young men like them" using an open-minded, unbiased approach. They recommended that we avoid referring to it as a "serious" study.

\section{Adolescent Communication Preferences}

Most participants preferred a journal format to a one-on-one interview to discuss sensitive topics such as urinary or sexual issues with healthcare researchers. For example, one participant stated, "I think [I would definitely rather fill out a journal] by myself. I think some of these things are sensitive to talk about and if it makes you look weird you're not going to tell the researcher about it, like you're not going to say it." If there were going to be individual qualitative interviews, they preferred a male interviewer or a choice of interviewer gender. They had several recommendations about how to conduct focus groups with hypospadias patients. First, they suggested that focus group participants should have an opportunity to meet each other and engage in conversation for an hour before the focus group starts. Second, they recommended that the focus group leader start the session by describing the potential problems with urinary and sexual function in hypospadias patients to see if they could relate. They thought that the majority of high school-age participants would be mature enough to talk about sexual subjects in a focus group setting. They expressed some concerns about focus group participation 
for younger hypospadias patients, due to their lack of maturity and discomfort about discussing their medical history with strangers. Third, participants suggested a focus group of patients with "sexual disabilities" due to a variety of conditions including hypospadias would be "more inclusive" and "invite people to share their experiences." Finally, they suggested that, in the future, a focus group leader with a history of hypospadias repair would be preferable given their first-hand experience of the condition.

\section{Discussion}

We decided to engage male adolescents without a clinical history of hypospadias to provide insight into healthcare communication preferences of adolescents and provide feedback about the initial draft of a toolkit to elicit patient-centered outcomes about hypospadias. Comparing the views of "normal" respondents provides the basis for developing tools uniquely suited to the needs of those needing hypospadias repair.

In experimental methods, a control group is a group that receives the standard of care or is "untreated". It is compared with an experimental group that receives and intervention or treatment. Differences between the two groups are calculated as the treatment effect. A similar concept in qualitative research concerns the use of a "comparison group," however, what is being compared may be attitudes, beliefs and meaning. [18] In this study the long term goal is to develop a toolkit for understanding adolescents in need of hypospadias repair. In order to best understand the particular needs of this population is it useful to have a comparator, in this case normal adolescents and their approach to delicate or potentially embarrassing topics like sexual function. Comparing the views of "normal" respondents provides the background or basis for developing tools uniquely suited to the needs of those needing hypospadias repair.

We included patient-generated "priority domains" for hypospadias based on the work of Keays et al.[11] Focus group participants emphasized the importance of using an unbiased, supportive and 
open-ended approach with serious language to encourage hypospadias patients to share sensitive information about urinary and sexual function, penile appearance and overall quality of life. They specifically discouraged the use of statements implying any type of disability or dysfunction, cautioned against statements that could pressure the patient into providing answers and recommended avoidance of a "test-like" appearance. These suggestions diverge from current methods of assessing hypospadias outcomes that primarily consist of multiple choice questionnaires that are limited in scope and do not provide the opportunity for creative expression or open-ended responses.

The participants' preference for a gender congruent interviewer for research studies reflects the prior work of Lee et al who noted that approximately $70 \%$ of participants preferred a gender congruent clinician when discussing sex during a well-child visit.[13] Female participants were significantly more likely to prefer a gender-congruent clinician than male participants.[13] Prior evidence of adolescents' reluctance to participate in research studies may be rooted in concerns about confidentiality. Mustanski et al. suggested several steps that researchers could take to facilitate informed decision making about research participation and ensure minors' safety in the absence of parental permission.[14] These included incorporating multimedia presentations into the consent process and explaining researchers' motivations for conducting the study.[14]

One limitation of this study is that the limited population sampled limits generalizability and our findings may not be similar to adolescents with a history of hypospadias repair. Furthermore, some students may have felt uncomfortable discussing sensitive issues in a group setting. On the other hand, the study provides a rich description of a group of male high school students' experiences with healthcare providers and researchers. Another limitation of this study is the potential loss of data during analysis of focus group transcripts such as intonations of voice, body language and seating arrangements that can add meaning to the textual data.[19] Finally, it is possible that the focus group was too 
structured by the use of a draft journal the investigators had created without any prior input from the target population. Though given the participant population without a history of hypospadias, this allowed for more targeted and relevant feedback for the larger study this informs. In addition, we believe the insights offered are valuable given the lack of qualitative research in this area to date.

One advantage of focus groups over individual interviews for research is that the group process helps people to identify and clarify their views.[20] The group functions as a promoter of synergy and spontaneity by encouraging participants to comment, explain, disagree and share their views. This process encourages participants to share experiences and voice opinions that might not surface during individual interviews. $[21,22]$ Although it takes more time and effort to organize focus groups and they create more logistical challenges than individual interviews do, they may yield deeper insights into the problem under investigation.[23, 24] Although we cannot compare the toolkit feedback we would have obtained in individual interviews to the data we collected in the focus group, we observed a lively discussion and group synergy during both of our focus groups with the majority of participants contributing significantly to the discussion.

In future studies, we will pilot test the toolkit with a small group of adolescents with a history of hypospadias repair as children in order to further refine the tool. In addition, we will explore preferences for alternative communication methods such as artificial intelligence (e.g. "Alexa"), and questionnaires on social media outlets (e.g. Facebook or Reddit).

\section{Conclusions}

This exploratory study identified important concepts about language and communication preferences among adolescent males regarding urinary and sexual issues that were not previously identified in the pediatric urologic literature. Participants preferred a toolkit format with colorful graphics, clinical, non-judgmental language and open-ended responses to encourage reporting of 
sensitive urinary, sexual and psychosocial issues. Based on focus group feedback we revised the toolkit's content and appearance in effort to improve the acceptability and usability in this patient population.

\section{Conflict of interest}

The authors have no conflicts of interest to disclose.

\section{References}

[1] Vandendriessche S, Baeyens D, Van Hoecke E, Indekeu A, Hoebeke P. Body image and sexuality in adolescents after hypospadias surgery. Journal of pediatric urology. 2010;6:54-9.

[2] Andersson M, Sjostrom S, Wangqvist M, Ortqvist L, Nordenskjold A, Holmdahl G. Psychosocial and Sexual Outcomes in Adolescents following Surgery for Proximal Hypospadias in Childhood. The Journal of urology. 2018.

[3] van den Dungen IAL, Rynja SP, Bosch J, de Jong T, de Kort LMO. Comparison of preputioplasty and circumcision in distal hypospadias correction: long-term follow-up. Journal of pediatric urology. 2018.

[4] Thiry S, Saussez T, Dormeus S, Tombal B, Wese FX, Feyaerts A. Long-Term Functional, Cosmetic and Sexual Outcomes of Hypospadias Correction Performed in Childhood. Urol Int. 2015;95:137-41.

[5] Fraumann SA, Stephany HA, Clayton DB, Thomas JC, Pope JCt, Adams MC, et al. Long-term follow-up of children who underwent severe hypospadias repair using an online survey with validated questionnaires. Journal of pediatric urology. 2014;10:446-50.

[6] Chertin B, Natsheh A, Ben-Zion I, Prat D, Kocherov S, Farkas A, et al. Objective and subjective sexual outcomes in adult patients after hypospadias repair performed in childhood. The Journal of urology. 2013;190:1556-60.

[7] Rynja SP, de Jong TP, Bosch JL, de Kort LM. Functional, cosmetic and psychosexual results in adult men who underwent hypospadias correction in childhood. Journal of pediatric urology. 2011;7:504-15. [8] Howe AS, Hanna MK. Management of 220 adolescents and adults with complications of hypospadias repair during childhood. Asian J Urol. 2017;4:14-7.

[9] Rynja SP, de Jong T, Bosch J, de Kort LMO. Proximal hypospadias treated with a transverse preputial island tube: long-term functional, sexual, and cosmetic outcomes. BJU international. 2018;122:463-71. [10] Sullivan KJ, Hunter Z, Andrioli V, Guerra L, Leonard M, Klassen A, et al. Assessing quality of life of patients with hypospadias: A systematic review of validated patient-reported outcome instruments. Journal of pediatric urology. 2017;13:19-27.

[11] Keays MA, Starke N, Lee SC, Bernstein I, Snodgrass WT, Bush NC. Patient Reported Outcomes in Preoperative and Postoperative Patients with Hypospadias. The Journal of urology. 2016;195:1215-20.

[12] Ghidini F, Sekulovic S, Castagnetti M. Parental Decisional Regret after Primary Distal Hypospadias Repair: Family and Surgery Variables, and Repair Outcomes. The Journal of urology. 2015.

[13] Lee EC. Adolescent Preferences for Topics Addressed During Well Visits. WMJ. 2017;116:210-4. 
[14] Mustanski B, Coventry R, Macapagal K, Arbeit MR, Fisher CB. Sexual and Gender Minority Adolescents' Views On HIV Research Participation and Parental Permission: A Mixed-Methods Study. Perspect Sex Reprod Health. 2017;49:111-21.

[15] Kyilleh JM, Tabong PT, Konlaan BB. Adolescents' reproductive health knowledge, choices and factors affecting reproductive health choices: a qualitative study in the West Gonja District in Northern region, Ghana. BMC Int Health Hum Rights. 2018;18:6.

[16] Mbadu Muanda F, Gahungu NP, Wood F, Bertrand JT. Attitudes toward sexual and reproductive health among adolescents and young people in urban and rural DR Congo. Reprod Health. 2018;15:74. [17] Hsieh HF, Shannon SE. Three approaches to qualitative content analysis. Qualitative health research. 2005;15:1277-88.

[18] Lewis-Beck, M. S., Bryman, A., \& Futing Liao, T. The SAGE encyclopedia of social science research methods. 2004, Thousand Oaks, CA: Sage Publications, Inc.

[19] Greenwood M, Kendrick T, Davies H, Gill FJ. Hearing voices: Comparing two methods for analysis of focus group data. Appl Nurs Res. 2017;35:90-3.

[20] Kitzinger J. Qualitative research. Introducing focus groups. BMJ. 1995;311:299-302.

[21] Carey M. The group effect in focus groups: Planning, implementing and interpreting focus group research. In: Morse J, editor. Critical issues in qualitative research methods. Thousand Oaks, CA: Sage; 1994. p. 225-41.

[22] Stewart DW SPaRD. Focus groups: Theory and practice. Thousand Oaks, CA: Sage; 2007.

[23] Coenen M, Stamm TA, Stucki G, Cieza A. Individual interviews and focus groups in patients with rheumatoid arthritis: a comparison of two qualitative methods. Qual Life Res. 2012;21:359-70.

[24] Kingry MJ, Tiedje LB, Friedman LL. Focus groups: a research technique for nursing. Nurs Res. 1990;39:124-5. 
Figure 1: Participants' suggestions for revision of the introductory page of the toolkit

Figure 2: Participants' suggestions for revision of a scale of emotions related to hypospadias

Figure 3: Participants' suggestions for revision of a Likert scale about the impact of hypospadias 
Table 1: Proposed Topics and Guiding Questions for Focus Groups

\begin{tabular}{|c|c|}
\hline Topic & Guiding Questions and Prompts \\
\hline Appearance of toolkit & $\begin{array}{l}\text { "What do you think about the appearance of this page [of the toolkit]? } \\
\text { Do you have any suggestions about how to improve it? } \\
\text { (Inquire about graphics, color choices, sufficient space for open-ended } \\
\text { responses etc.) }\end{array}$ \\
\hline Content of toolkit & $\begin{array}{l}\text { "What do you think about the content of this page [of the toolkit]? } \\
\text { Do you have any suggestions about how to improve it? } \\
\text { (Inquire about overall tone, word choice, clarity of written exercises, } \\
\text { opportunities for freedom of expression, etc.) }\end{array}$ \\
\hline $\begin{array}{l}\text { Preferred format for } \\
\text { interactions with healthcare } \\
\text { researchers }\end{array}$ & $\begin{array}{l}\text { "If you were to participate in a research study about sensitive issues } \\
\text { like urination or sex, what format would you prefer for sharing this } \\
\text { type of information with researchers?" } \\
\text { "Why would you prefer that format?" }\end{array}$ \\
\hline $\begin{array}{l}\text { Preferred interviewer } \\
\text { gender }\end{array}$ & $\begin{array}{l}\text { "If you were to participate in a research study about sensitive issues } \\
\text { like urination or sex would you prefer a certain gender for the } \\
\text { researcher?" } \\
\text { "Why would you prefer that gender?" }\end{array}$ \\
\hline $\begin{array}{l}\text { Suggestions for focus groups } \\
\text { with hypospadias patients }\end{array}$ & $\begin{array}{l}\text { "Do you have any suggestions about how we could have successful } \\
\text { focus group with patients who had a history of hypospadias repair as } \\
\text { children?" }\end{array}$ \\
\hline $\begin{array}{l}\text { Preferred language for } \\
\text { interactions with healthcare } \\
\text { researchers }\end{array}$ & $\begin{array}{l}\text { "When discussing sensitive issues with healthcare researchers what } \\
\text { type of language do you prefer they use?" } \\
\text { (clinical, serious language versus colloquial language) }\end{array}$ \\
\hline
\end{tabular}


BEFORE



- "My thought on it is that lighter colors make it look like more inviting." (1)

- "I kind of see the goldish color being a little bit on the darker side. I think a lighter color, or some color, would be better." (1)

- "I think you guys should add some statistics to the book." (2)

- "...like some graphs and stuff like that. That could fill the void." (2)

- “...where it says hypospadias... instead of adding like a picture or illustration of it, you could add a graph or something about the percentage of people with hypospadias in the country." (2)
AFTER

\section{WHAT IS HYPOSPADIAS?}

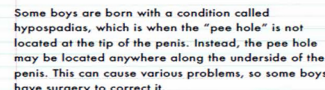

ay be located anywhere along the underside of the

bevo ursery to corme a


Downloaded for Anonymous User (n/a) at Indiana University - Ruth Lilly Medical Library from ClinicalKey-com by Elsevier on April 29, 2019. For personal use only. No other uses without permission. Copyright @2019. Elsevier Inc. All rights reserved. 


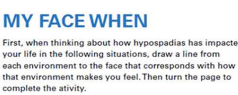

Bathroom At Home

Public Bathroom with Locking Door

Doctor's Office

Hom

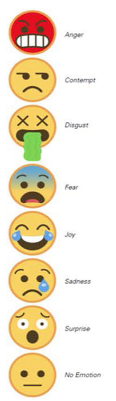

- "I think they should be able to assign more than one emotion to each, and then maybe like give them a line to explain." (1)

- "Would have have emojis after each of those settings like 'Bathroom at Home', and then a set of emojis, and then 'Public Bathroom', as set of emojis going horizontal." (1)

"Embarrassment would be a good one to add." (2)

- "I think it would be good if you added like just like a few lines to write like your own specific feeling about it instead of putting so many other like emojis. I "mean, you could probably just give like what they feel." (2)

\section{MY FACE WHEN}

Think about how your hypospadias surgery is currently impacing your tie in the following sivarions and circle (or we emoip faces that correspond with how

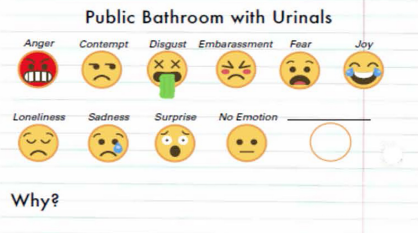

Downloaded for Anonymous User (n/a) at Indiana University - Ruth Lilly Medical Library from ClinicalKey.com by Elsevier on April 29, 2019. For personal use only. No other uses without permission. Copyright @2019. Elsevier Inc. All rights reserved 
BEFORE

\section{SCALES}

How do you feel hypospadias has affected you in different areas of your life? Fill in a corresponding section of each scale to indicate the impact on you.
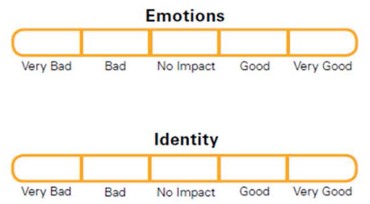

Outlook on Life

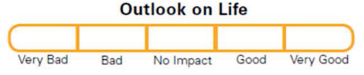

\section{RECOMMENDATIONS}

- "if you want to like really understand why they clicked 'very good' or 'no impact', maybe you would ... have the box, and then maybe have two lines, like, 'why did you pick this?', to understand their understanding behind it." (1)

- 'Because some people pick 'very good' for reasons, so like maybe if you want your research to be more stable or more consistent." (1)

- "I also feel like there should be an option where, after you fill in the scales and write your different emotions and the way it's impacted you, you should also have a section where a person could write out. Because sometimes this might lead you to express yourself in a different way than just the scales." (2)

*1=suburban school, 2=urban school

\section{AFTER}

\section{SCALES}

Fill in the corresponding segments of each scole to indicate life ond then oxplain your rety might have impacted your life and then explain your rating. It you ore unsure what a
topic is, please refer back to the "Goetting Storted" section.
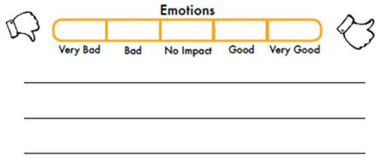

Q 0 Identity
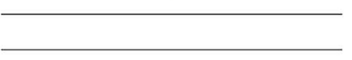

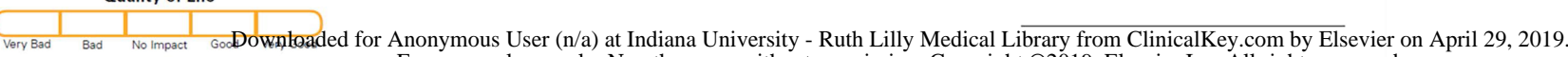
For personal use only. No other uses without permission. Copyright (O2019. Elsevier Inc. All rights reserved. 
Extended Summary Table: Themes and Representative Quotes Regarding Toolkit Appearance/Content

\begin{tabular}{|c|c|}
\hline Theme/Recommendation & Representative Quote \\
\hline \multirow[t]{2}{*}{ Make it educational } & $\begin{array}{l}\text { "I think you guys should add some statistics to the book...like some graphs and stuff } \\
\text { like that. That could fill the void." (\#2) }\end{array}$ \\
\hline & $\begin{array}{l}\text { "Would it be helpful to have a picture of like hypospadias? Like what it looks like when } \\
\text { they're a baby?" (\#2) }\end{array}$ \\
\hline \multirow[t]{3}{*}{$\begin{array}{l}\text { Avoid "test-like" } \\
\text { appearance and content }\end{array}$} & $\begin{array}{l}\text { "Maybe adding some color would be useful because like, I'm not going to lie, I feel like } \\
\text { this looks a lot like a test." (\#1)" }\end{array}$ \\
\hline & $\begin{array}{l}\text { "I would change 'answers' to 'responses' so they think it's not like a test or something. } \\
\text { Instead of adding like a picture or illustration of it you could add like a graph or } \\
\text { something about the percentage of people with hypospadias in the country." (\#1) }\end{array}$ \\
\hline & $\begin{array}{l}\text { "Could you emphasize the fact that you don't have to use up all the lines? It could look } \\
\text { really exhausting to a person doing it." (\#1) }\end{array}$ \\
\hline $\begin{array}{l}\text { Avoid biasing the } \\
\text { patient's responses }\end{array}$ & $\begin{array}{l}\text { "With kind of the imposing diction used, where is says 'this can cause problems'...the } \\
\text { word choice "problems" makes it seem like you had to get surgery. By using the word } \\
\text { "problems" that it's going to affect you later on. Like maybe a lighter word...that's } \\
\text { what I was thinking....issues." (\#1) }\end{array}$ \\
\hline $\begin{array}{l}\text { Make patients feel } \\
\text { comfortable }\end{array}$ & $\begin{array}{l}\text { "We should emphasize that there is nothing wrong with you for having this surgery } \\
\text { and it's completely natural. Maybe that would help them feel like sharing their } \\
\text { experience." (\#1) }\end{array}$ \\
\hline $\begin{array}{l}\text { Avoid pressuring the } \\
\text { patient to respond to the } \\
\text { questions }\end{array}$ & $\begin{array}{l}\text { "[It] says, "after we receive your completed journal", and I think that makes the person } \\
\text { more inclined to answer any questions they might not want to just to complete the } \\
\text { journal. So, if you just put, "After we receive your responses..."' (\#1) }\end{array}$ \\
\hline $\begin{array}{l}\text { Avoid implying } \\
\text { "wrongness" }\end{array}$ & $\begin{array}{l}\text { "I feel like using the word 'correct' [the hypospadias] can make them feel more like an } \\
\text { outcast and you can probably change it to 'surgery on the condition' to make them feel } \\
\text { it's something that could be fixed." (\#1) }\end{array}$ \\
\hline $\begin{array}{l}\text { Use professional } \\
\text { language }\end{array}$ & $\begin{array}{l}\text { "I think you should use 'urination' instead of 'peeing', just because peeing is like } \\
\text { something like big kids, like } 13 \text { and 14, kind of giggle over something like that. } \\
\text { Urination makes it seem a little bit more professional." (\#1) }\end{array}$ \\
\hline Be serious, not silly & $\begin{array}{l}\text { "I think it's fine if you're not using medical jargon. It's using words you'd hear every } \\
\text { day. But, I don't think it should be like too playful because it is still a serious study. But, } \\
\text { if you're saying 'Mark Your Territory,' then that might like mislead them. Also the } \\
\text { person being studied might not appreciate that there is a little bit of humor in this }\end{array}$ \\
\hline
\end{tabular}




\begin{tabular}{|l|l|}
\hline & $\begin{array}{l}\text { topic. If he feels a little bit insecure, he might not appreciate, like terms like 'Mark Your } \\
\text { Territory"."(\#1) }\end{array}$ \\
\hline $\begin{array}{l}\text { Encourage freedom of } \\
\text { expression }\end{array}$ & $\begin{array}{l}\text { "Maybe for the options you could add like a choice where you could write your own. } \\
\text { With all these options here, just so you have something else there." (\#1) }\end{array}$ \\
\hline $\begin{array}{l}\text { Include a variety of } \\
\text { emotions }\end{array}$ & $\begin{array}{l}\text { "I think you should add an emotion describing loneliness to describe when you feel } \\
\text { you're dealing with the situation all on your own and you don't really have anyone to } \\
\text { talk to." (\#2) }\end{array}$ \\
\hline $\begin{array}{l}\text { Avoid big or excessive } \\
\text { words }\end{array}$ & $\begin{array}{l}\text { "I would just avoid using excessive words. So...I would just put, "If you've ever felt } \\
\text { insecure or felt the need to hide your surgery from others, explain why." (\#1) }\end{array}$ \\
\hline & $\begin{array}{l}\text { "Maybe like definitions to some words that people may not know or maybe just cancel } \\
\text { them out like I don't know what nonchalant means." (\#1) }\end{array}$ \\
\hline & $\begin{array}{l}\text { "I don't feel like [sexual function] is a word people would use but I get the meaning } \\
\text { behind it." (\#2) }\end{array}$ \\
\hline
\end{tabular}

\#1=first focus group; \#2=second focus group 